\title{
SURGICAL MANAGEMENT OF HORIZONTAL ROOT FRACTURE WITH PLATELET RICH FIBRIN (PRF) PLACEMENT: CASE REPORT OF TWO CASES
}

\author{
Dr Parul Bansal ${ }^{1}$, Dr Kalpana Kanyal ${ }^{2}$, Dr Vineeta Nikhil ${ }^{3}$
}

1. Reader, Department of Conservative dentistry and Endodontics, Subharti Dental College, Meerut, Uttar Pradesh, (India)

2. Lecturer, Department of Conservative dentistry and Endodontics, Subharti Dental College, Meerut, Uttar Pradesh, (India)

3. Prof. \& Head Department of Conservative dentistry and Endodontics, Subharti Dental College, Meerut, Uttar Pradesh, (India)

Corresponding Author:

${ }^{1}$ Mobile: 918791114280 Email: docparulbansal@gmail.com

\begin{tabular}{|l|}
\hline Received: \\
$1^{\text {st }}$ June, 2013 \\
Accepted: \\
$20^{\text {th }}$ August, 2013 \\
Available online: \\
$25^{\text {th }}$ August, 2013
\end{tabular}

Received:

$1^{\text {st }}$ June, 2013

Accepted:

$20^{\text {th }}$ August, 2013

Available online:
Radicular fractures in permanent teeth are uncommon injuries among dental traumas, being only $0.5-7 \%$ of the cases. Horizontal root fractures can be managed endodontically or combined endodontic and surgical approach. Treatment varies according to the displacement and vitality of the fragments. This paper presents a case report of two cases of horizontal root fracture, present between the middle and apical third of central incisors, which were managed by combined endodontic and surgical approach, while in second case it was followed by PRF placement to facilitate osteoinduction and periodontal tissue regeneration.

Keywords: Tooth fracture, Dental radiography, Regeneration

\section{INTRODUCTION}

Radicular fractures are defined as those that involve cementum, dentin and the pulp. Horizontal root fractures are frequently observed in the maxillary anterior region in the 11-20 years age group male patients. ${ }^{1}$ Such fractures may occur in the cervical third, middle third or apical third of the root. The most common types of root fractures are in the middle third of the root $(57 \%)$, followed by fracture in the apical part (34\%), and in coronal part $(9 \%)^{2,3}$ Majority of root fractures have been shown to undergo healing. It has been reported that $77 \%$ of root fractured teeth healed, with pulp necrosis occurring in $20 \%$ cases. $^{2}$ Healing with granulation tissue is a sign of pulp necrosis and an indication that endodontic treatment of coronal portion of the tooth is necessary. ${ }^{4}$ In both the cases displacement of apical segment with necrosis of coronal segments was present. Both the cases were managed by endodontic treatment of coronal segments and surgical removal of apical segments. To enhance the bony healing and periodontal tissue regeneration, in second case platelet rich fibrin was placed into the bony cavity. ${ }^{5}$

\section{CASE REPORT}

\section{Case I}

A male patient aged 24, reported with chief complain of pain and intermittent pus discharge from his upper front teeth. Patient gave history of trauma 8 years back. On clinical and radiographic examination horizontal root fracture of right central incisor was diagnosed (Figure 1). Fractures were present at the junction of middle and apical third of the root and apical segment was displaced from its anatomical position. No increased mobility of the coronal segments was found. Coronal segments were found necrosed on vitality testing. Endodontic treatment of coronal segment was planned till the fracture line. After Access opening, working length radiograph was taken, calcium hydroxide dressing was placed for $1 \mathrm{wk}$. In next visit, an apical barrier was created using MTA. After $24 \mathrm{hrs,} \mathrm{obturation} \mathrm{was} \mathrm{done} \mathrm{till} \mathrm{the}$ fracture line. In next visit, surgical removal of an apical segment was performed and radiograph was taken (Figures 2, 3). At 6 months, patient was asymptomatic and follow up radiograph was taken (Figure 4). 


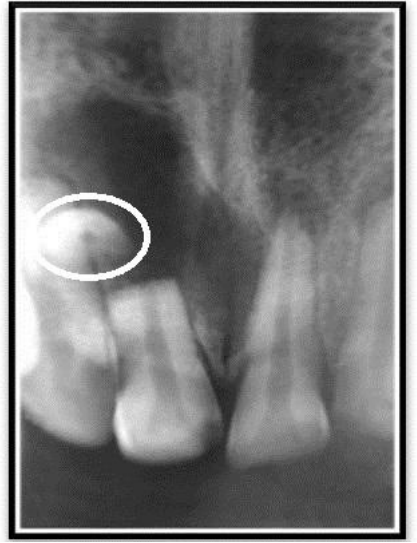

Figure 1: Preoperative radiograph revealing displaced fractured root segment.

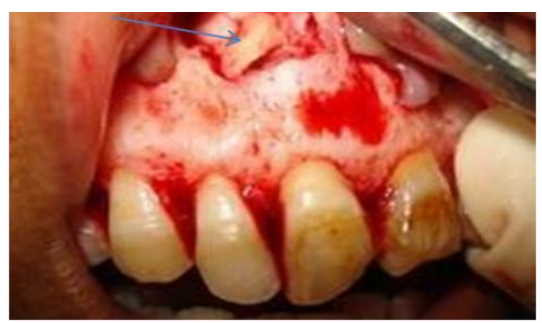

Figure 2: Fractured root fragment insitu.

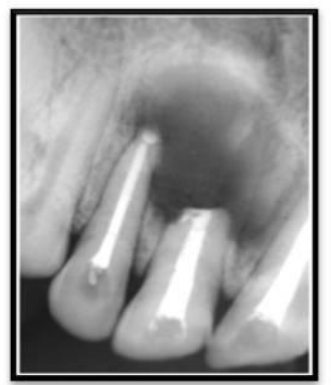

Figure 3: Post operative radiograph.

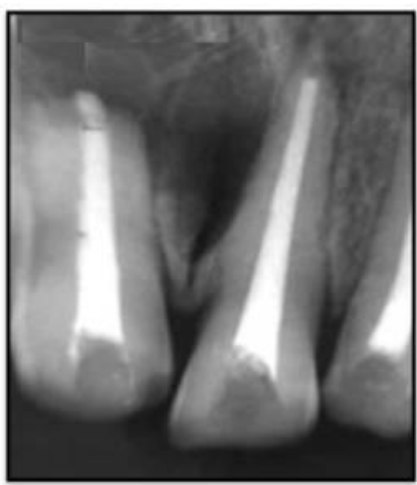

Figure 4: Follow up at 6 months

\section{Case II}

A male patient aged 22 Years presented with chief complain of intermittent pain and fracture of his upper front teeth. Patient gave history of trauma 10 years back. Preoperative radiograph showed the horizontal root fracture present at the junction of middle and apical third of the root (Figure 5). In this case also, an apical segment was displaced from its anatomical position. No increased mobility of the coronal segment was found. Coronal segment was found necrosed on vitality testing. Similarly, endodontic treatment of coronal segment till the fracture line followed by surgical removal of apical segments was performed (Figure 6). In this patient, bony hard apical stop was present at fracture line so no apical barrier was needed. After removal of apical segment, curettage of bony cavity was done. Bony cavity was filled with plasma rich fibrin made up of patient own blood, to facilitate bony healing (Figure 7). Flap was gently placed back to its original place and suture was placed. Patients were reviewed after one weak for suture removal and the healing at the surgical site was uneventful. Then patient was followed after 1 month (Figure 8) and to be followed after 6 months.

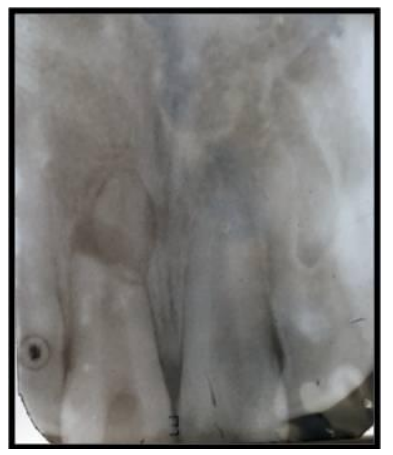

Figure 5: Preoperative radiograph revealing mid root fracture.

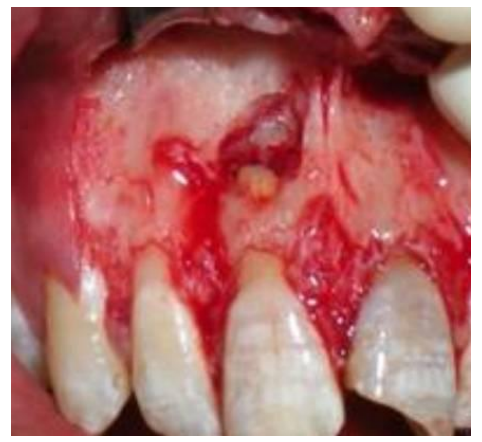

Figure 6: Fractured root segment in situ. 


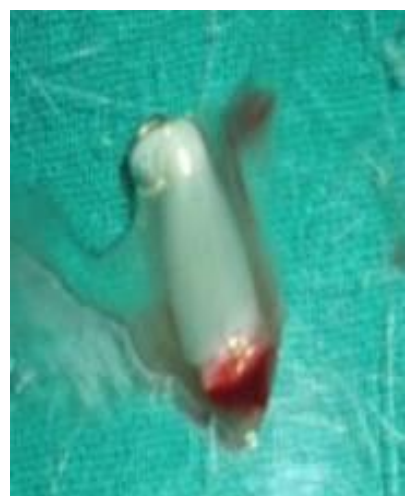

Figure 7: Prepared platelet rich fibrin

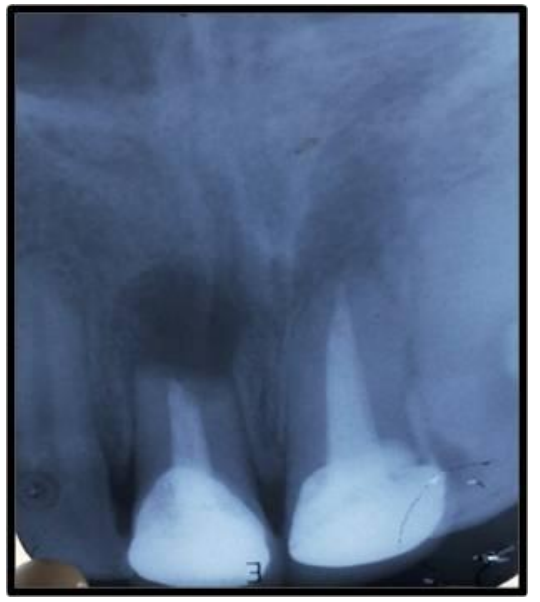

Figure 8. Follow up at 1 month.

\section{DISCUSSION}

Several studies have reported that the average age of patients with root fractures lies between 11 and 20 years. ${ }^{3}$ The prognosis for tooth survival following a horizontal root fracture can be summarized as quite $\operatorname{good}^{6}$. Consequently, the prognosis of the tooth is influenced by the factors such as the patient's age, the stage of root growth, mobility of the coronal fragment, dislocation of the coronal fragment, and fragment diastasis. Communication between the palatal sulcus and the fracture line can negatively influence the prognosis. ${ }^{7,8}$

The choice of treatment depend on radiographic features, such as periradicular changes, the width of the root canal space and the amount of separation of two fragments. 3,9 Dental treatment may not be necessary in cases of root fracture where there is no mobility or displacement of the coronal segment, and if the patient has no apparent complaints. ${ }^{9,10}$
Root fractures heal differently depending on the degree of separation of the fragments, the severity of injury, and the ability of the pulp to heal. ${ }^{6}$ The histological reactions at the fracture line are categorized into four types: (I) interposition of calcified tissue (callus formation); (II) interposition of connective tissue, which is characterized by peripheral rounding of the fracture's ends; (III) interposition of bone and connective tissue, radiologically characterized by the clear separation of the two fragments; and (IV) interposition of granulation tissue, caused by an infected or necrotic pulp. The last mode of healing with granulation tissue is a sign of pulp necrosis and an indication that endodontic treatment of the coronal portion of the tooth is required. However, if the pulp injury is severe, healing does not occur and granulation tissue separates the fractured segments, obviously without the hard-tissue healing. ${ }^{6,10}$ In the present cases radiographic evaluation demonstrated the presence of mid root fracture and a separation of apical segment from coronal segment leaving a space more than 2 $\mathrm{mm}$ between the two fragments. The extent of fracture and development of pathology at fracture site necessitated a surgical approach. Various materials can be used to close the root canal at the fracture site like MTA and biodentin. In first case MTA was used to create an apical barrier at the fracture site. MTA has been reported to have superior biocompatibility, sealing ability and is less cytotoxic than other materials currently used in pulpal therapy. ${ }^{11}$ Bone regeneration after surgical intervention takes place in a very slow manner. Hence, to enhance these processes a number of bone substitutes are being tried out. Enhancement of the regenerative process of human body by utilizing the patient's own blood is a unique concept in dentistry. Blood and blood products have been used for over a century for various purposes. PRF is a matrix of autologous fibrin, in which are embedded a large quantity of platelet and leukocyte cytokines during centrifugation. PRF acts as a bioactive scaffold for periodontal tissue regeneration. Application of PRF has two major benefits: (a) The promotion of soft tissue healing, (b) the induction of new alveolar bone formation. ${ }^{12,13}$ PRF is a by-product of the patient's 
own blood; therefore, chances of infectious disease transmission is rare.

\section{CONCLUSION}

Treatment of root fracture depends on various factors such as position of fracture line, mobility of tooth and pulpal status. Follow up is of critical importance. PRF placement after surgical removal gave a good radiographic outcome in a short period of one month. 6 months follow up needs to be done.

\section{REFERENCES}

1. Brandini DA, Poi WR, Panzarini SR. Integrated treatment to resolve a horizontal root fracture. Dent Traumatol. 2009;25(2):e16-20.

2. Cvek M, Andreason JO, Borum MK. Healing of 208 intraalveolar root fractures in patients aged 7-17 yrs. Endod Dent Traumatol 2001;17:53-62.

3. Aras MH, Ozcan E, Zorba YO, Aslan M. Treatment of traumatized maxillary permanent lateral and central incisors horizontal root fractures.Indian J Det Res 2008;19(4):354-6.

4. Andreason JO, Andreason FM, Mejare I, Cvek M. 1 Healing of 400 intraalveolar root fractures. 2. Effect of treatment factors such as treatment delay, repositioning, splinting type and period and antibiotics. Dent tramatol 2004;20:192-202.
5. Dohan DM, Choukroun J, Diss A. Platelet rich fibrin: second generation platelet concentrate. Part I: technological concepts and evolution. Oral Sug, Oral Med, Oral Path, Oral Rad and Endod 2006;101(3):e37-e44.

6. Trop M, Chivian N, Sigurdsson A. Traumatic injuries.In: Cohen S, Burns RC, editors. Pathways of the pulp. St. Louis: Mosby; 1998.p. 567-72.

7. Caliskan MK, Pehlivan Y. Prognosis of root fractured permanent incisors. Endod Dent Taumatolol 1996;12,129136.

8. Andrea B, Von Arx T. Permanent teeth with horizontal root fractures after dental trauma. Research and science 2010;120:200-6.

9. Andreason FM, Andreason JO, Bayer T. Prognosis of root fractured permanent incisors- predictation of healing modalities. Endod Dent Tramatol 1989;5:11-22.

10. Malhotra N. A Review of root fractures: Diagnosis, treatment and prognosis. Dent Update 2011;38:615-28

11. Altinok B, Kargul B. Case report: Use of Mineral trioxide aggregate in permanent incisors with horizontal root fractures: A five year follow up. Oral Health and Dental Management. 2010;9:223-8.

12. Mazumdar P, Nag D, Bhunia S. Treatment of Periapical Lesion with Platelet Rich Fibrin. Indian Medical Gazette Jan 2013:28-33.

13. Nathan E. Carlson, Robert BR. Platelet-rich plasma Clinical applications in Dentistry. J Am Dent Assoc 2002;133:13836. 